\title{
ARTIFICIAL NEURAL NETWORK MODEL FOR PREDICTING DISCHARGE BELOW GATES
}

\begin{abstract}
Amen, K.A.
Civil Engineering Department, Faculty of Engineering, Assiut University

(Received January 19, 2008 Accepted March 9, 2008)

Gate in general, a device in which a leaf or a member is moved across the water from external position to control or stop the flow. Under flow gates commonly used to regulate and measure flow in hydraulic structures. In this paper, Multiplayer feed forward Artificial Network (ANN) with back propagation algorithm is used to develop a computational model to predict discharge below gates. A network of size 3-9-1 is found suitable for this purpose with 540 iterations and hyperbolic tangent (tanch) activation function. The results of the trained, verified and tested ANN model are compared to the experimental measurements. The results indicated that the ANNs are powerful tools for modeling flow rates below gates.
\end{abstract}

\section{NOMENCLATURE}

$\mathrm{Fe} \quad=$ Froude number .

$G \quad=$ Gravitational acceleration.

$a \quad=$ is the gate opening.

$Y 1=$ Upstream water depth.

$Q \quad=$ discharge rate.

$B \quad=$ is the gate width.

$C_{d} \quad=$ is the gate discharge coefficient.

\section{INTODUCTION AND REVIEW}

Gates are those elements used for closing and opening surface or deep openings in a hydraulic structure. The most frequently used type of gates is the vertical sluice gates. A gate has to be movable in order to fulfill its function. Consequently, considerable interest in the head-discharge relationship in turns is affected by the gate discharge coefficient $\mathrm{Cd}$.The characteristics of flow below sluice gates were discussed by numerous of investigators, see e.g. Ashour [1], 1991, Chan [2], 1973, Chow [3], 1959, Grishin [4], 1982, Larock [5], 1969, Lewies [6], 1977, Rajaratnam [7], 1967 and many others.

Flow under gate may be evaluated quite simply through the one-dimensional equation of energy (1). The more direct from of the discharge relationship is the following (see figure (1)):

$$
Q=C_{d} a B \sqrt{2 g y_{1}}
$$

Where $\quad C_{d} \quad$ is the gate discharge coefficient.

$Q \quad$ is the discharge.

$a \quad$ is the gate opening.

$B \quad$ is the gate width. 


\section{COLLECTION OF EXPERIMENTAL DATA}

The experimental data that is used to train, validate and test the ANN model were collected from Amen [8], 1998. The experimental data are collected using a horizontal flume of trapezoidal cross-section, $10.5 \mathrm{~m}$. long, $0.40 \mathrm{~m}$ bottom width, $0.85 \mathrm{~m}$. high and side slope 1:1. The flume is equipped with a tail gate to control the tail water depth. A centrifugal pump lifts water from underground sump to the flume inlet. The gates are made from steel and few millimeters than the flume width of $40 \mathrm{~cm}$. Small rubber slices were fixed on both ends of each gate model.

The discharge was measured by a calibrated right angle V-notch installed at end of the channel basin.

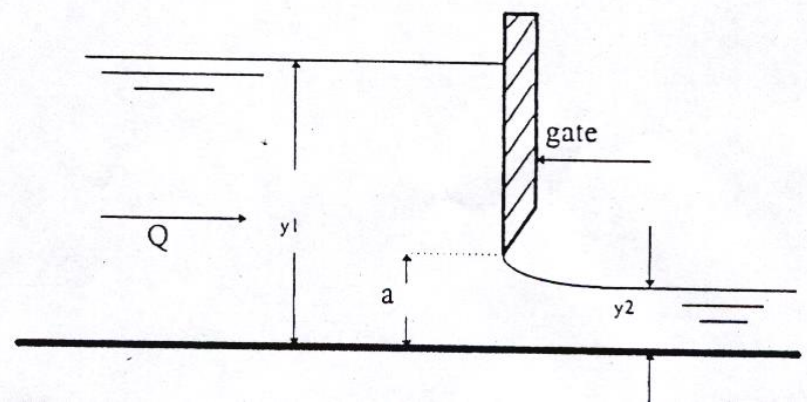

Figure (1) Definition sketch for flow below gate

\section{BASICS PRINCIPLES OF ARTIFICIAL NEURAL NETWORKS}

Artificial neural networks or simply neural networks are a new way of analyzing data. They have a unique ability to learn complex patterns and trends in the data emulating the human ability to solve complicated problems. Therefore, neural computing is based on the way that biological system, such as human brain works. The human brain is made up of many neurons. Each of the brain cells is connected to many others in a network that adopts and changes as the brain learns. In neural computing processing elements (PE) replace the neurons and these PEs are linked together to form neural networks. Each PE performs a simple task. It is the connections between the PEs that give neural networks the ability to learn patterns and interrelationship in data through the certain weights associated to the connections PEs.most of the applications of ANNs in fields of water Engineering were reviewed in Negm [9] . The most important tool of ANN applied in this study is the multi-layer perceptron (MLP), which is a neural network modeling, tooling that optimized for prediction and forecasting applications. The MLP can be used to classify patterns or to predict values from data. The network consists of three layers as shown in Fig. (2). Input layer of 3 neurons to represent the variables a/y1, Fe and $\mathrm{Re}$. An output layer to represent the single output variable $\mathrm{Cd}$. The hidden layer between the input and the output layer to receive the input, to perform the computations and to the send the outputs to the output layer. The hidden layer uses a transfer or activation function to modify the input to the neuron. The transfer function may be linear, sigmoid or tanch are smooth nonlinear functions and one of them is normally chosen because the learning algorithm requires a response function with a continuous, single-valued first derivative. 
In terms of mathematics, the following steps summaries the network training processes based on back-propagation learning algorithm, Neural Connection, Negm[9].

i- The values of the weights are set to initial random values

ii- The normalized input pattern $X p(\mathrm{a} / \mathrm{y} 1, \mathrm{Fe}, \mathrm{Re})$ and the normalized target pattern $T p\left(C_{d}\right)$ are shown to the network.

iii- The output $(\mathrm{O})$ from each node in a layer is calculated. The output from a node $\mathrm{j}$ in the second layer is given by :

$O_{j}=\phi\left(\sum_{i=1}^{n} w_{i j} x_{i}+b_{j}\right)$

where: $\phi=$ the activation or transfer function of the node. The activation function $\Phi$ in the present application is the hyperbolic tangent function (tanch) and $\mathrm{bj}$ is the bias weight of the node $\mathrm{j}$.

iv- The weight (w) between nodes are adjusted, starting from the output layer and working backwards as follows:

$$
w_{i j}(s+1)=w_{i j}(s)+\eta \delta_{p j} O_{p j}
$$

where: $w_{i j}(s)=$ the weight between nodes $i$ and $j$ at step s before adjustment;

$w_{i j}(s+1)=$ The same weight after adjustment;

$O_{p j}=$ The output value at node $j$;

$\delta_{p j}=$ The error of pattern $p$ at node $j$ and

$\eta=$ The learning rate.

The error $\delta_{p j}$ is given by

$$
\delta_{p j}=O_{p j}\left(1-O_{p j}\right)\left(T_{p j}-O_{p j}\right)
$$

The steps from ii to iv are repeated until the error between the desired and the neural network output reaches a global minimum.

Figure (2) shows the developed network of size (3-9-1) to predict the coefficient of discharge $C_{d}$. The network consists of three layers. Input layer of 3 neurons to represent the variables a/y1, Fe, and Re, output layer to represent the single output variable $C_{d}$, and the hidden layer between the input and the output layer to receive the input, to perform the computations and to send the outputs to output layer.

$$
\text { Input layer Hidden layer Output layer }
$$

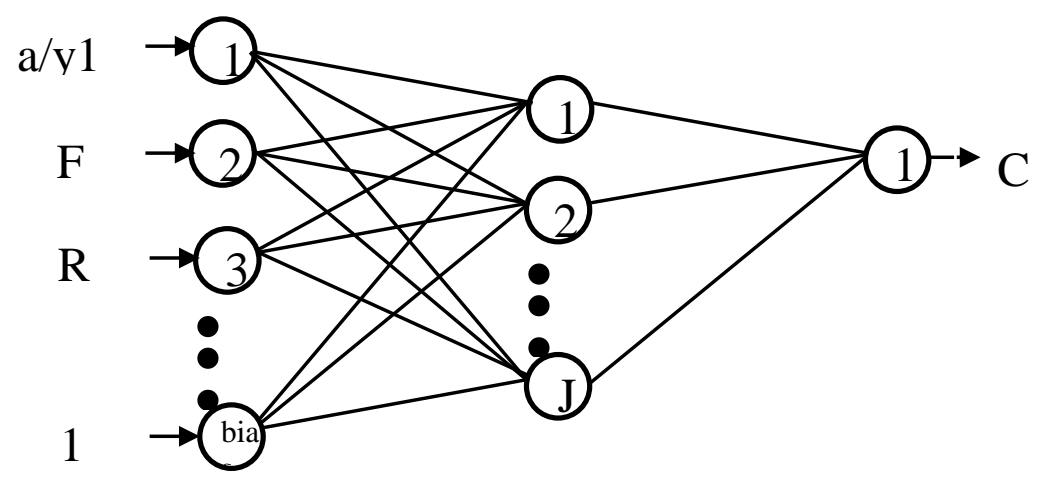

Figure (2) The multiplayer feed forward back propagation ANN 


\section{RESULTS OF THE DEVELOPED ANN MODEL}

Many computer experiments were conducted to determine the best initial range of the weights of the network connections, the best activation function, the best number of neurons in the hidden layer and the best number of iterations, see figures (3), (5), (6), and (7). Then the network stability was checked. Analysis of the results of the conducted experiments indicated that

- The best range to initialize the weight matrix was +0.2 .

- The best activation function was tanch.

- The best number of neurons in the hidden layer was 9 neurons.

- The best number of iterations was 1000 iterations (maximum updates).

Figure (3) shows the comparison between the predication of the best network (3-9-1) and the experiment data. The figure indicated that fair agreement was obtained.

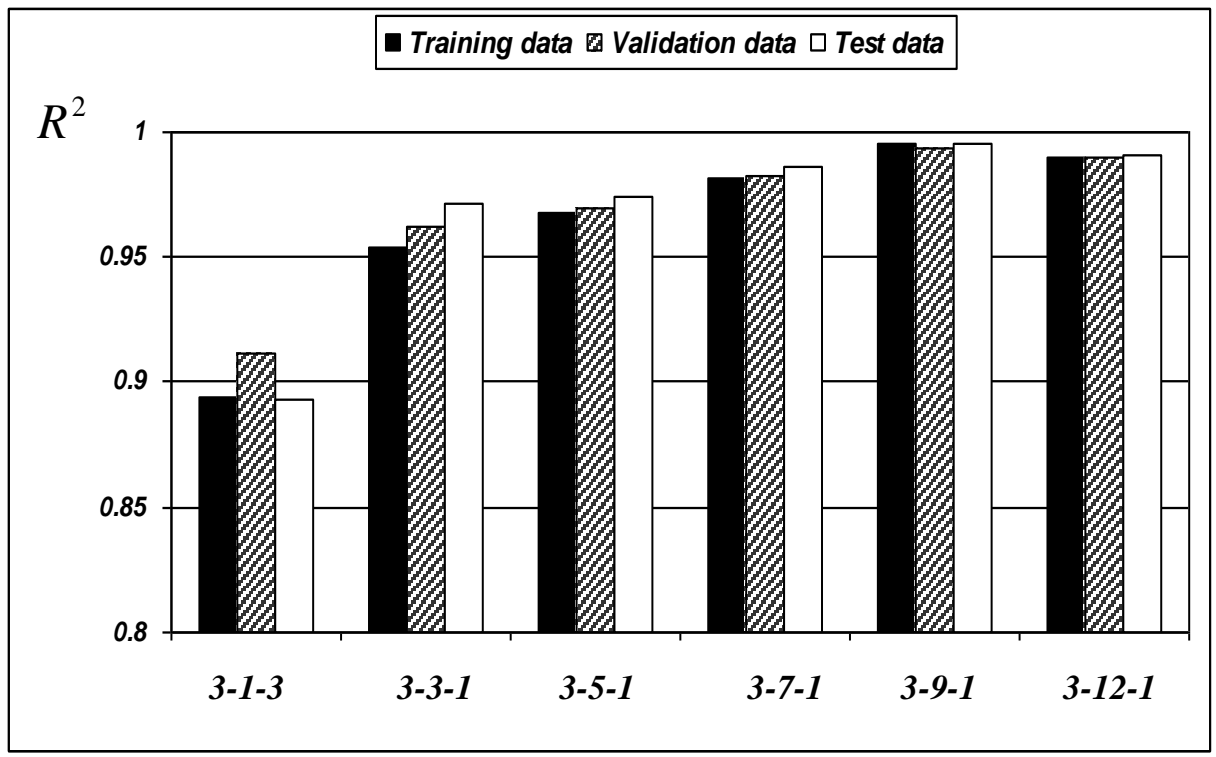

Fig • (3) Values of R-squared versus Number of hidden neurons 


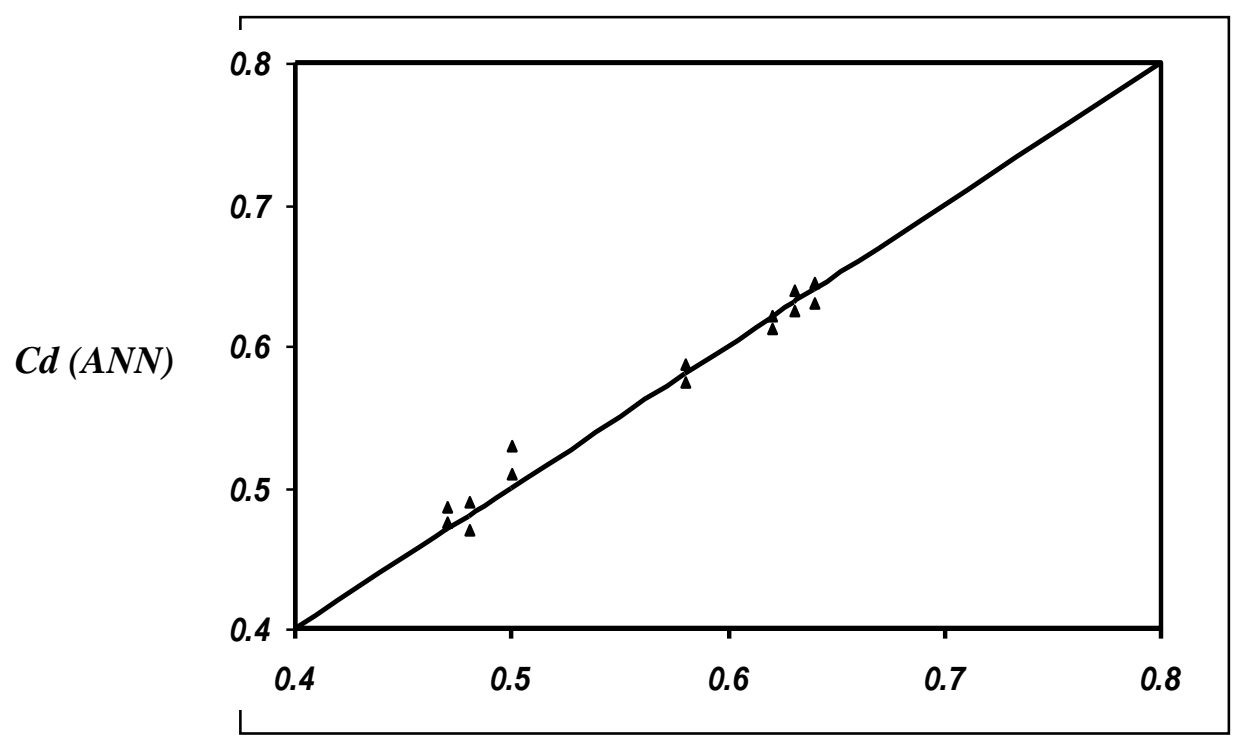

Cd (Exp.)

Fig. (4) Comparison between experimental Cd and those predicted by ANN
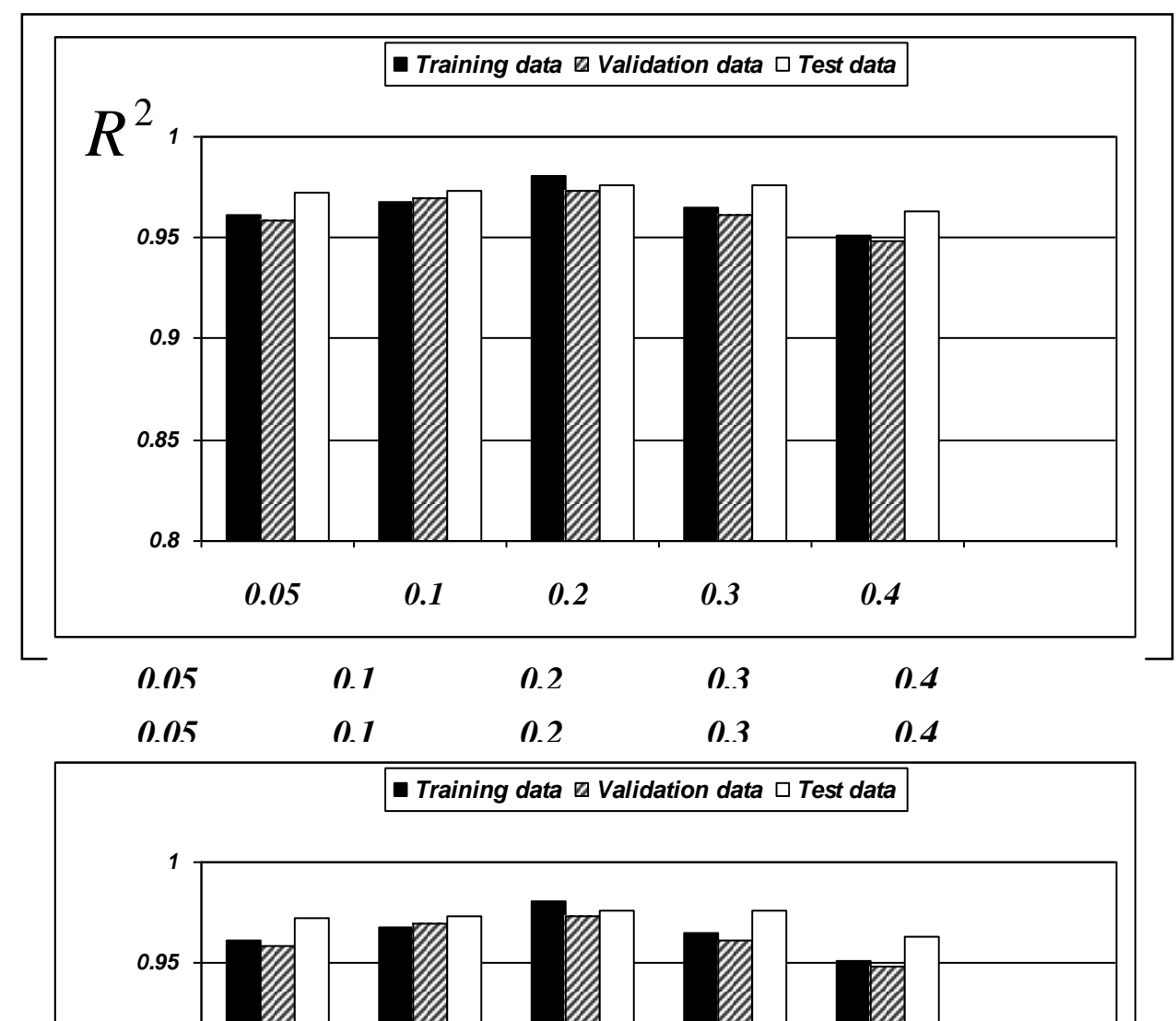


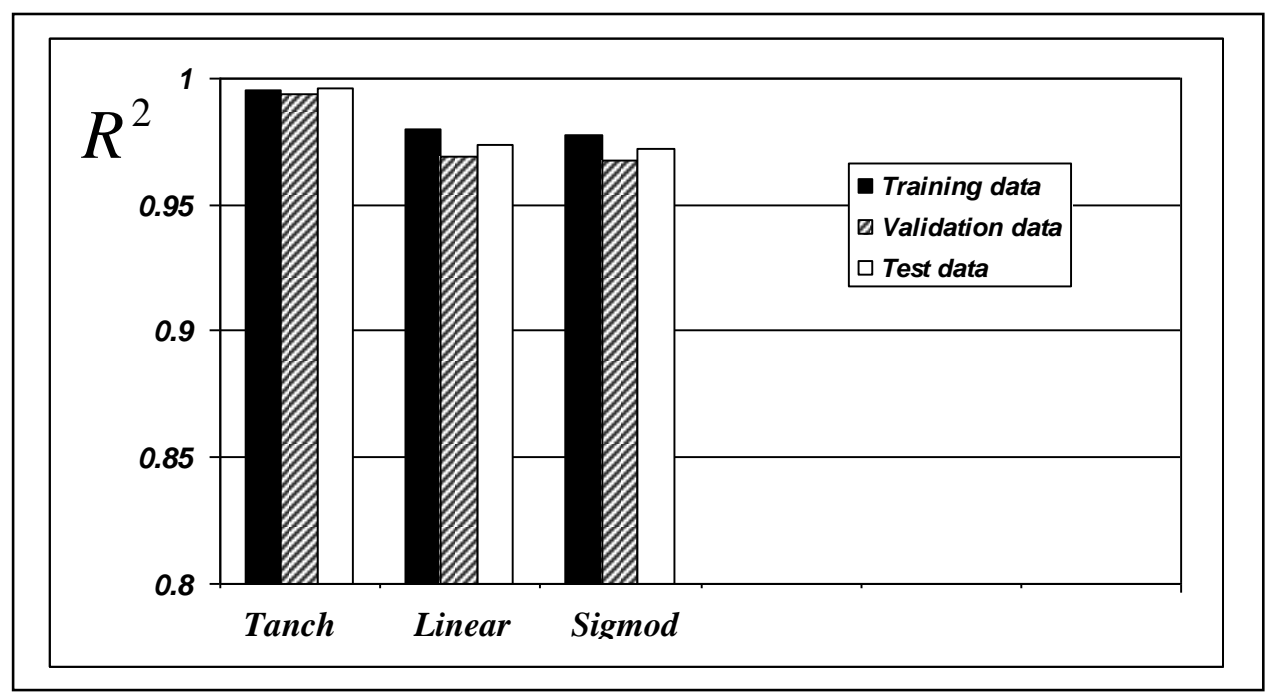

Fig . (6) Values of R-squared versus activation function

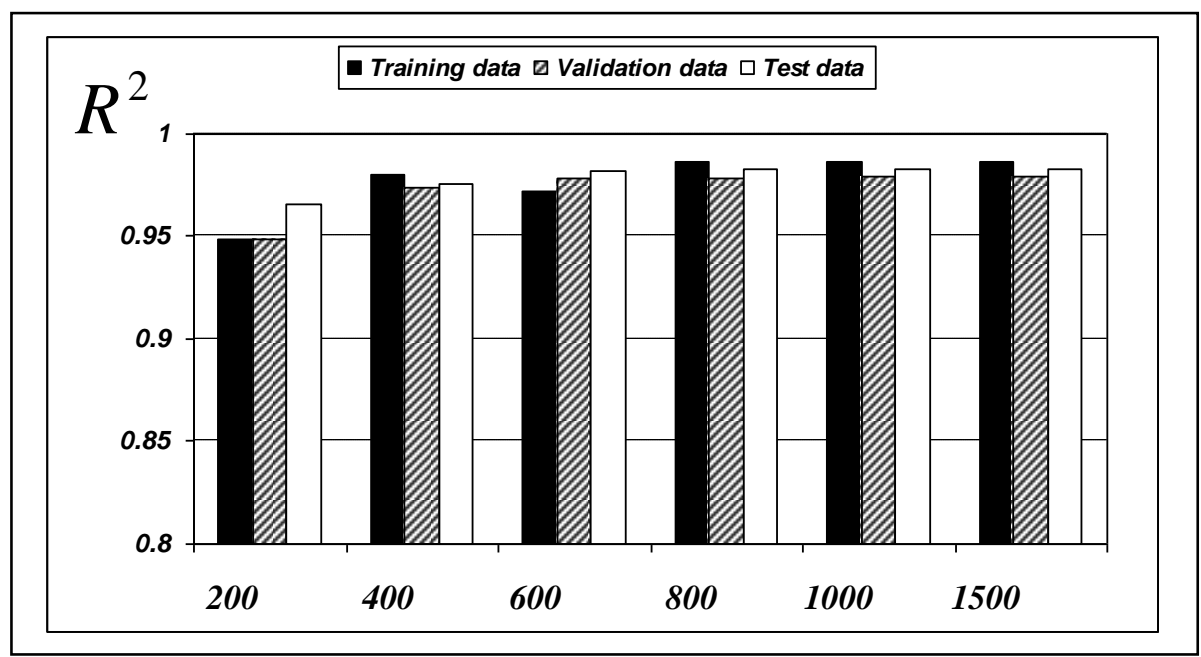

Fig . (7) Values of R-squared versus No. of Iterations

\section{CONCLUSIONS}

1- The predicted discharge coefficient is found to be dependent on the ratio between gate opening and the depth of water in the upstream, Froude number and Reynolds number.

2- There are agreements between experimental data and ANN model.

3- Decreasing the Froude number is creating larger discharge coefficient.

4- Increasing the Reynolds number is creating larger discharge coefficient 


\section{REFERENCES}

1- Ashour , M.A ., "The Effect of Irrigation Structure Gate - Shapes on the Discharge coefficients “, Bulletin of the Faculty of Engineering, Vol. 19 , July 1991 , Part 2.

2- Chan. S.T.K., Larock, B.E., And Herrmann, L.R., " Free surface Ideal Fluid Flows “, Proc. ASCE, J.Hyd., Div., Vol. 99, No. HY6, June, 1973 PP. 959-974 .

3- Chow, V.T. “ Open channel hydraulics " Mc Graw- Hill Book Co. ,Inc., New York, N.Y., 1959

4- Grishin, M.M "Hydraulic Structures " Mir Publishers, Moscow, Vol. $2,1982$.

5- Larock, B.E., " Gravity - Affected Flow From Planar Sluice Gates " Proc. ASCE, J.Div., Vol. 95 , No. HY 4, July, 1969, PP. 1213- 1223.

6- Lewies T, Isaacs, “ Numerical Solution for Under Sluice Gates " Proc. ASCE , J.HYD, Vol. 103, No. HY 5, May1977.

7- Rajaratnam, $N$., and Subramanya, K., "Flow Equation For the Sluice Gate " Journal of the Irrigation and Drainage Division ASCE , Vol. 93 , No. IR3, Proc. Paper 5436, Sept. 1967,pp. 167-186.

8- Amen, K.A., " The Effect of Irrigation Structure Gate- Shapes on The Discharge Coefficent "M.Sc. Thesis Dec.1998.

9- Negm, A.M., " Applications of Artifical Neural Networks In Hydraulics " First Draft of No. 2, Faculty of Eng., Zagazig University, Zagazig Egypt.

\section{استخدام الثبكات العصبية الاصطناعية للتنبؤ بالتصرف أسفل البوابات}

تستخدم بوبات منشات الري عادة في تتظيم توزيع مياه الري بالإضافة إلى استخدامها كاداه بسيطة

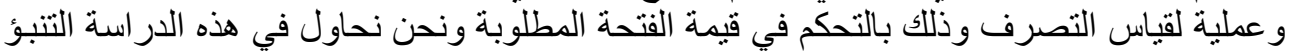

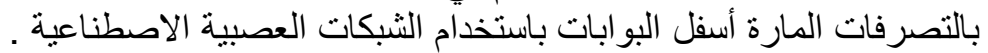

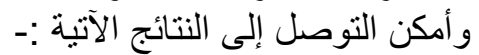

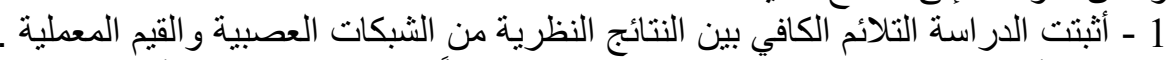

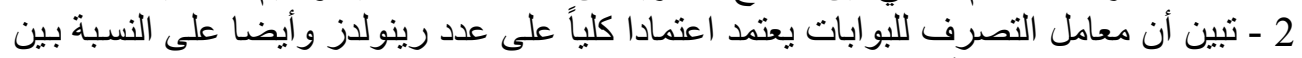
فتحة البو ابة و العمق في الأمام.

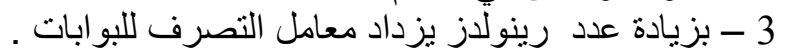

